\title{
Comparative Study of Periapical Radiographic Techniques with Apex Locator for Endodontic Working Length Estimation: An ex vivo Study
}

Vaishali Parekh, Chirag Taluja

\begin{abstract}
Background: Accurate assessment of working length determines the success and prognosis of an endodontic treatment outcome. Various methods are used in determining the working length.
\end{abstract}

Aim: Compare the measurements of the apex locator and
radiographic technique to determine working length.

Methods: An ex vivo study was conducted on 20 patients having intact single straight root canal. Only premolars were taken in the study. After doing coronal flaring and irrigation, the radiographic length was determined with an aid of a k-type file and electronic length (EL-Root-ZX) 3rd generation apex locator. After extraction of all the premolars, stereomicroscope was further used to confirm and compare radiographic and electronic apex locator.

Results: A mean value of $0.5430 \pm 0.5741 \mathrm{~mm}$ was observed among radiographic techniques. A mean value of $0.4240 \pm$ $0.4587 \mathrm{~mm}$ was observed among apex locator techniques. Ttest revealed, no significant difference between the two techniques was observed ( $p=0.615)$. 'Two tailed' t-test revealed intragroup significance both techniques for determining the working length.

Conclusion: The distance of the apical foramen to the tip of the file: A mean value of $0.4240 \pm 0.4587 \mathrm{~mm}$ with apex locator technique was observed. Working length of apex locator was more in comparison to radiographic technique. No significant difference between the two techniques was observed $(p=0.615)$. Intragroup significance among both techniques for determining the working length was also observed. However, a further study incorporating a larger sample size and utilization of both techniques of working length determination on the same tooth has to be conducted.

Clinical significance: Combining the apex locator technique and radiographic technique for determination of working length would yield more accurate working length.

Keywords: Apex locator, Radiographic technique, Stereomicroscope, Working length.

How to cite this article: Parekh V, Taluja C. Comparative Study of Periapical Radiographic Techniques with Apex Locator for
Endodontic Working Length Estimation: An ex vivo Study. J Contemp Dent Pract 2011;12(2):131-134.

Source of support: Nil

Conflict of interest: None declared

\section{INTRODUCTION}

Insufficient cleaning of the canal or damaging of periapical tissues from overinstrumentation is a possibility when accurate working length is not determined. ${ }^{1,2}$

The cementodentinal junction (CDJ) which is also described as the apical constriction is the anatomical and histological landmark where the periodontal ligament begins and the pulp ends. ${ }^{1,2}$ Hence, prognosis of endodontic treatment is mainly dependent on proper establishment of working length and comprehensive obturation of canals. Root canal preparation techniques aim to end the biomechanical instrumentation at the apical constriction. ${ }^{3}$ Majority of studies conclude that optimal rates of healing occur when instrumentation, debridement, disinfection and filling are contained within the region of apical constriction. ${ }^{1}$

The location of the apical constriction and CDJ cannot be identified clinically. ${ }^{1,2}$ Hence, a lot of variation in different roots and its relationship to the CDJ is observed.

Traditional methods for establishing working length include the use of radiography, ${ }^{2,4}$ anatomical averages and knowledge of anatomy, ${ }^{5,6}$ tactile sensation and moisture on a paper point. All of these methods have limitations. ${ }^{7}$ Therefore, these methods for root canal measurement do not allow precise localization of apical constriction and CDJ.

Sunada in 1962 introduced the principle of the 'biological characteristics theory' into clinical practice, stating that the EALs could read the apex by measuring the differences of electrical resistance values between the periodontal ligament and the oral mucosa. 
Lee et al (2002) reported in their study that most of the file tips ended at the major foramen regardless of the existence of a detectable CDJ suggesting that the major foramen was more reproducible compared with the CDJ for accuracy studies.

Since we could not find any apparent literature comparing standardized periapical radiographic techniques with apex locator for endodontic working length estimation utilizing the coronal reference point and major apical foramen we made an attempt to clarify it.

\section{MATERIALS AND METHODS}

An ex vivo study was conducted on a total of 20 singlerooted premolars going to be extracted due to periodontal problems. Patients were randomly selected and divided into two equal groups of 10 patients each whose canal lengths were determined. In one group radiographic method of working length and in another group apex locator was used. Permission from the ethical committee was taken and patient consent was also obtained before conducting a study. Fully erupted nonrestored single canal premolars, radiographically visible canal having fully formed root apices with no apical resorption, absence of severe curvatures and adequate tooth structure only were included in the study.

Teeth with open apices, cracks and root fracture, anatomical variations, severe curvatures, calcifications and narrow pulp space were excluded. All teeth were performed for standardized procedures for access opening. For fixed reference points all cusps were flattened with tapered diamond bur.

Determination of working length by root ZX apex locator: A total of 10 premolars working length were determined by root ZX apex locator. The file was penetrated slowly into the canal until the apex locator indicated flashing bar at the 'APEX' (Fig. 1).

\section{Determination of Working Length by Radiographic Method}

The radiographic determination point for each canal was determined with standardized radiograph technique using extension cone paralleling (XCP) device and placement of $\mathrm{k}$-file in the canal (Fig. 2).

After determination of working length by both the techniques silicon stopper on the inserted file was then set to the flat buccal cusp tip and the file was cemented in place with glass ionomer cement (Ketac-fil; ESPE, Norristown, PA). After the cement was completely set, the file handles were removed using tapered fissure burs. The rubber stoppers were removed and the teeth were extracted (Fig. 3).

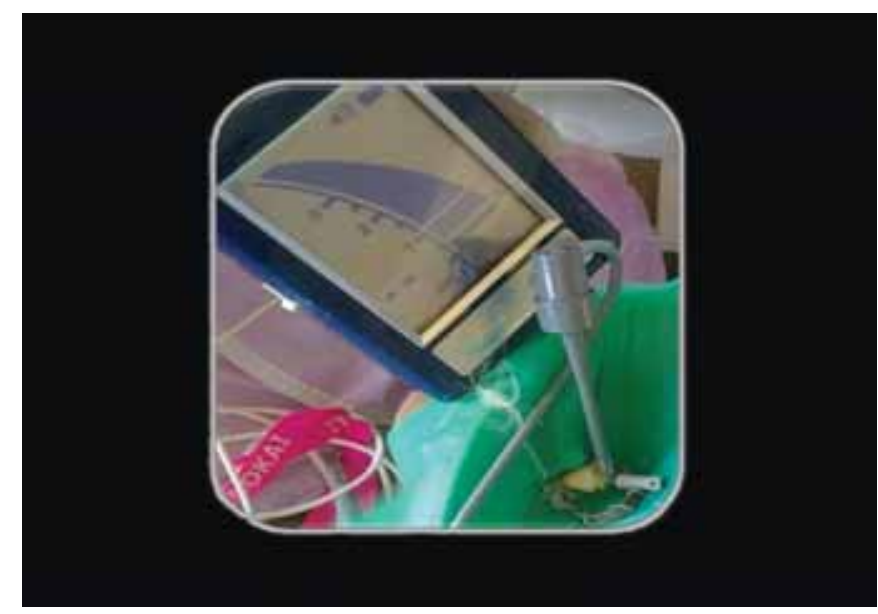

Fig. 1: Root ZX apex locator

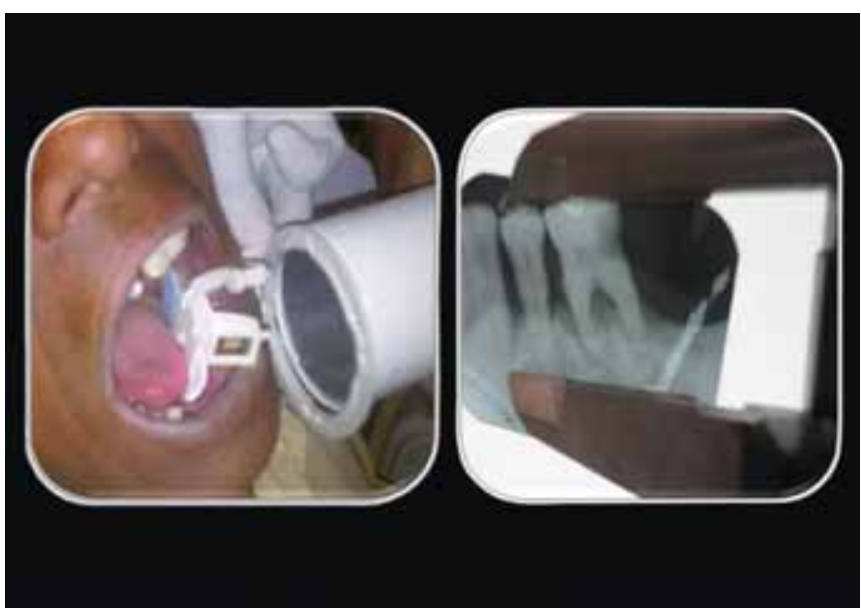

Fig. 2: Extension cone paralleling $(\mathrm{XCP})$ device

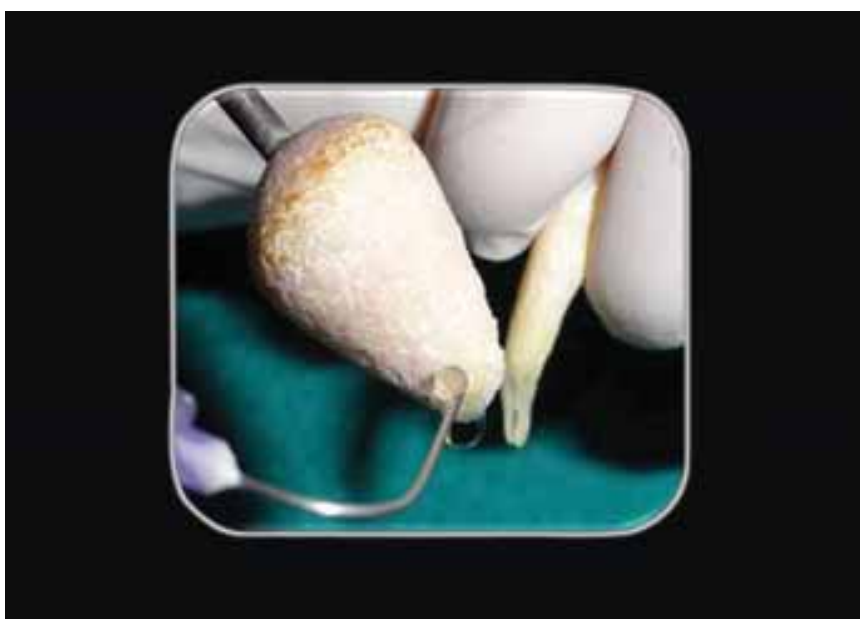

Fig. 3: Trimming of buccal wall of the root

\section{Stereomicroscopic Assessment of Working Length}

All extracted teeth from both the groups were cleaned of residual soft tissues. The buccal wall of the roots at its apical 4 to $5 \mathrm{~mm}$ of all roots were trimmed with fine stones and sof-lex (3M ESPE dental products, St Paul, MN) discs to gradually expose the inserted files, taking care not to disturb the apical anatomy (Fig. 4). 


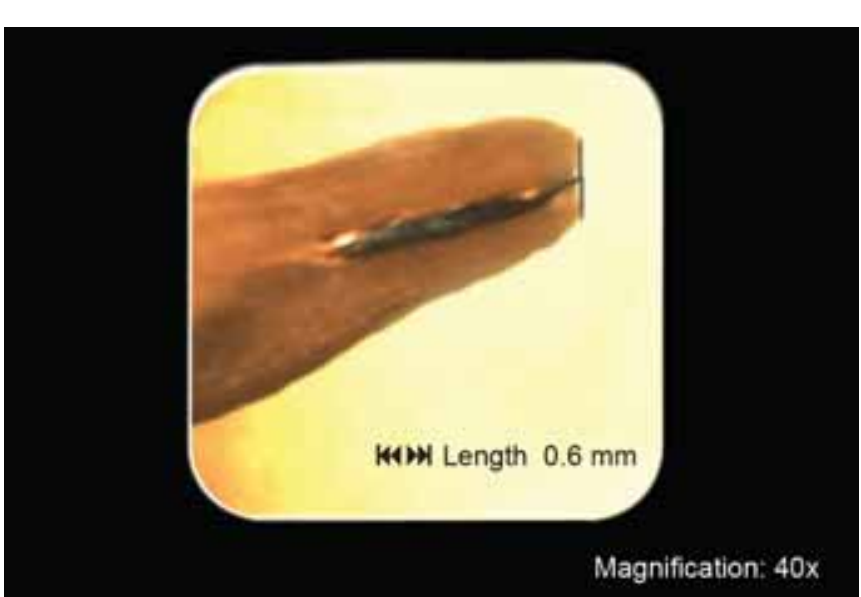

Fig. 4: Stereomicroscopic evaluation of working length

The exposed file tip in relation to the apical root anatomy was examined under stereomicroscope (Motis $40 \mathrm{x}$ ) and the pictures were captured by using digital camera connected to the personal computer. Measurements were done with image analysis software (Image J, 1.41; NH, Bethesda, MD) and its distance to the apical foramen was measured to the nearest hundredth of millimeter.

\section{Statistical Analysis}

SPSS 16.0 version software was used for statistical analysis. A confidence interval of $95 \%$ and a significance level of $5 \%$ were set. Mean value, standard deviation of both the techniques were determined. t-test was used to determine statistical significance between both the techniques. A two tailed t-test was used to determine statistical significance among the samples in each group for both the techniques.

\section{RESULTS}

A mean value of $0.5430 \pm 0.5741 \mathrm{~mm}$ was observed among radiographic technique (Table 1 ). A mean value of 0.4240 $\pm 0.4587 \mathrm{~mm}$ was observed among apex locator technique (Table 2).

t-test revealed, no significant difference between the two techniques was observed ( $\mathrm{p}=0.615)$.

'Two tailed' t-test revealed intragroup significance among both techniques for determining the working length (Table 3).

\section{DISCUSSION}

Determination of working length is crucial for treatment and prognosis for an endodontic treatment. The distance

Table 1: Mean value of radiographic technique
\begin{tabular}{cccccc}
\hline No. of samples & Total & Mean & Variance & Std dev \\
\hline 10 & 4.2400 & 0.4240 & 0.2104 & 0.4587 \\
\hline \multicolumn{6}{c}{ Table 2: Mean value of apex locator technique } \\
\hline \\
\hline No. of samples & Total & Mean & Variance & Std dev \\
\hline 10 & 5.4300 & 0.5430 & 0.3296 & 0.5741 \\
\hline
\end{tabular}

between coronal reference point and apical constriction represents the working length of individual teeth. Earlier studies revealed numerous inconsistencies and variations with regard to the apical constriction and coronal reference point and their inter-relationship. The apical foramen is a more reliable apical reference point in determining WL..$^{8-11}$ The highest point on the cusp tip represents coronal reference point. Probability of slippage of silicon rubber stop on cusp tip was observed to be more. Since variation was observed in recording of apical constriction and coronal reference point we modified our study by taking alternative land marks. The major apical foramen instead of apical constriction and coronal reference point was recorded after flattening the cusp tip, so that a stable reference is obtained was used as reference points to determine the working length. Radiographic and apex locator techniques are the most commonly used techniques to determine the working length.

Determining the apical foramen as the reference point gives more consistency than the apical constriction or radiographic apex. The use of the major foramen is more reproducible for accuracy studies. The radiographic method (RM) is probably still the most widely used method for determining WL. It reveals many important details and is useful in every endodontic procedure. However, it also has limitations and often provides an illusory image.

The location of the apical constriction and CDJ cannot be identified clinically. ${ }^{1,6,12}$ Hence, stereomicroscope was used to determine accurate measurement between the apical foramen and tip of the file.

The mean value of the distance from apical foramen and tip of the file with respect to apex locator was less in comparison to radiographic technique. This observation revealed that the working length determined by the apex locator was more nearer to the apical foramen than that of radiographic technique as observed in Tables 1 and 2 . Probable reasons for such an observation could be associated

\begin{tabular}{lcccccc}
\multicolumn{7}{c}{ Table 3: Comparison of both techniques of working length determination } \\
\hline Working length & $T$ & Df & Sig (2-tailed) & Mean difference & Lower & Upper \\
\hline Radiographic & 2.991 & 9 & 0.015 & 0.54300 & 0.1323 & 0.9537 \\
Apex & 2.923 & 9 & 0.017 & 0.42400 & 0.0959 & 0.7521 \\
\hline
\end{tabular}


with the technique sensitivity employed in apex locator technique or drawbacks associated with radiographic technique.

t-test revealed, no significant difference between the two techniques was observed $(p=0.615$ ). Proper standardization employed in the radiographic technique or a small sample size could be attributed to such an observation.

Two tailed t-test revealed intragroup significance among both techniques for determining the working length (Table 3). Since the same tooth was not employed for both the techniques of working length determination could be the reason for such an observation. However, a further study incorporating a larger sample size and utilization of both techniques of working length determination on the same tooth has to be conducted.

\section{CONCLUSION}

The distance of the apical foramen to the tip of the file: A mean value of $0.4240 \pm 0.4587 \mathrm{~mm}$ with apex locator technique was observed. Working length of apex locator was more in comparison to radiographic technique. No significant difference between the two techniques was observed ( $p=0.615)$. Intragroup significance among both techniques for determining the working length was also observed. However, a further study incorporating a larger sample size and utilization of both techniques of working length determination on the same tooth has to be conducted.

\section{CLINICAL SIGNIFICANCE}

Combining the apex locator technique and radiographic technique for determination of working length would yield more accurate working length.

\section{REFERENCES}

1. Hassanien Ebab E, Hasbem Abeer, Chalfin Henry. Histomorphometric study of the root apex of mandibular premolar teeth: An attempt to correlate working length measured with electronic and radiograph methods to various anatomic positions in the apical portion of the canal. J Endod April 2008; 34(4):408-12.

2. Lee SJ, Nam KC, Kim YJ, Kim DW. Clinical accuracy of a new apex locator with an automatic compensation circuit. J Endod Oct 2002; 28(10):706-09.

3. Mancini M, Felici R, Conte G, Costantini M, Cianconi L. Accuracy of three electronic apex locators in anterior and posterior teeth: An ex vivo study. J Endod May 2011; 37(5): 684-87.

4. Vieyra JP, Acosta J. Comparison of WL with radio and four electronic apex locators. Int Endod J June 2011;44(6):510-18.

5. Plotino G, Grande NM, Brigante L, Lesti B, Somma F. An ex vivo accuracy of three electronic apex locators: Root ZX, elements diagnostic unit and apex locator and propex. Int Endod J May 2006 39(5):408-14.

6. Gardern MPJ, Chandler NP. Electronic apex locators. Department of oral rehabilitation, School of Dentistry, Unit of Otago, Dunedin, New Zealand. Int Endod J 2004;37:425-37.
7. Higa RA, Adorno CG, Ebrahim AK, Suda H. Distance from file tip to the major apical foramen in relation to the numeric meter reading on the display of three different electronic apex locators. Int Endod J 2009;42:1065-70.

8. Aggarwal Vivek, Singla Mamta, Kabi Debipada. An in vitro evaluation of performance of two electronic root canal length measurement devices during retreatment of different obturating Materials. J Endod 2010;36:1526-30.

9. Oascon EA, Marselli M, Congi O. An in vivo comparison of WL determination of two frequency based electronic apex locators. Int Endodont Journal 2009;42:1026-31.

10. Situ Chris, Marshall Gordon, Baumgartner J Gaig. An in vivo comparison of the root ZX 11, the apex NRG XFR and mini apex locators by using rotary nickel titanium files. J Endod 2009;35(7):962-65.

11. Schmitd Ligia Buloto, Lim Tatiana De Castro, Eduardo Montenegro Luiz Chinellato, Bramante ClóvisMonteiro, Garcia Roberto Brandão. Comparison of radiographic measurements obtained with conventional an indirect digital imaging during endontic treatment. J Appl Oral Sci 2008;16(2):167-70.

12. Williams Clayton B, Joyce Anthony P, Roberts Steven. Comparison between in vivo radiographic working length determination and measurement after extraction. J Endod 2006;32:624-27.

13. Fouad AF, Krell KV, McKendry DJ, Koorbusch GF, Olson RA. Clinical evaluation of five electronic root canal length measuring instruments. J Endod Sep 1990;16(9):446-49.

14. McDonald, Hovland JE. In vitro evaluation of the reliability of the root ZX electronic apex locator. Int Endod J 1999;32(2): 120-23.

15. Olson AK. The ability of the radiograph to determine the location of the apical foramen. Int Endod J 1991;24(1):28-35.

16. Hedrick RT. Methodological considerations in the determination of working length. Int Endod J 2001;34(5):371-76.

17. Czerw RJ, Fulkerson MS, Donnelly JC, Walmann JO. In vitro evaluation of the accuracy of several electronic apex locators. J Endod Nov 1995;21(11):572-75.

18. Ellingsen MA, Hollender LG, Odont D, Harrington GW. Radiovisiography versus conventional radiography for detection of small instruments in endodontic length determination II. In vivo evaluation. J Endod Oct 1995;21(10):516-20.

19. Rushton VE, Shearer AC, Horner K, Czajka J. An in vitro comparison of 10 radiographic methods for working length estimation. International Endod J 1995;28(3):149-53.

20. Nguyen HQ, Kaufman AY, Komorowski RC, Friedman S. Electronic length measurement using small and large files in enlarged canals. Int Endod J 1996;29(6):359-64.

\section{ABOUT THE AUTHORS}

\section{Vaishali Parekh}

Professor and Head, Department of Conservative Dentistry and Endodontics, KM Shah Dental College and Hospital, Sumandeep Vidyapeeth, Vadodara, Gujarat, India

\section{Chirag Taluja \\ (Corresponding Author)}

Postgraduate Student, Department of Conservative Dentistry and Endodontics, KM Shah Dental College and Hospital, Waghodia Road Piparia, Vadodara-391760, Gujarat, India, Phone: 9825055042 9427382006, e-mail: drchiragtaluja@yahoo.com 